\title{
Outcomes-based approach to pharmacy curriculum review and redevelopment
}

\author{
M.C.C. Doria ${ }^{1,2^{*}}$ \\ ${ }^{1}$ Faculty of Pharmacy University of Santo Tomas, Manila \\ ${ }^{2}$ Department of Pharmacy Aquinas University of Legazpi, Legazpi City, Philippines
}

\begin{abstract}
This study examines the process of curriculum review and redevelopment used in the Faculty of Pharmacy in the University of Santo Tomas. It provides the application of evidence-based principles in the systematic investigation of curriculum effectiveness. Data and information are gathered with a view to propose a five-year Bachelor of Science in Pharmacy program reflecting an outcomes-based approach to curriculum development.

Quantitative to triangulation research design method is employed in the study. Informal random and open-ended questions were answered by the respondents, consisting of the Faculty of Pharmacy administrators, faculty members, graduating B.S. Pharmacy students, and Pharmacy alumni, representing the different pharmaceutical sectors.

The assessment and feedback identified the needs or gaps in the current curriculum of the existing four-year B.S. Pharmacy Program. Three major areas of revision in the existing Pharmacy Curriculum were concluded as needed: (1) introduce students to the professional practice of pharmacy at the onset of their Pharmacy education, (2) provide opportunities for students to practice what they learn in real-life environments, and (3) integrate related courses to reduce duplication of materials and increase relevance between subjects.
\end{abstract}

Keyword: learning outcomes, graduate attributes, curriculum, assessment, feedback

\section{INTRODUCTION}

Today's society is characterized by rapid change. The Pharmacy Curriculum needs continuing assessment and revision in order to adequately equip the students with skills and human values needed to become responsible and effective professionals. This concept is reflected in educational parlance through the body of learning experience that equips individuals with the desired skills and values that will help them reach their goals in life.

The ever-increasing demand for welltrained pharmacists implies the need for improving the Pharmacy Curriculum. The change in the Pharmacy curriculum is relevant because of the planned harmonization of higher education in Southeast Asia with the objective of increasing the international competitiveness of ASEAN higher education. In creating a common higher education space in Southeast Asia are as follows: greater mobility, widening access and choices, academic and research collaborations, enhanced collaboration on human capital investment, and the promotion of ASEAN and/or Southeast Asian within the fast-changing global higher education landscape ${ }^{1}$. In this scenario, pharmacy education needs to react to and anticipate professional and social change. It must renew its mission and update its learning objectives ${ }^{2}$. Recognizing the strengths, weaknesses, opportunities and threats of the educational system will be the bases for a plan of improved program and propose a functional Pharmacy Curriculum that shall provide more viable and relevant training for students in meeting the changing

*Corresponding author: mcdoria@ust.edu.ph 
pharmacist's role/s in a diverse array of health care settings.

\section{Statement of the problem}

The main problem of this study addresses each of the following: How can the proposed Pharmacy curriculum be made functional in order to produce Professional Pharmacists who are responsive to the needs of individuals, families and communities in today's society?

To solve the foregoing problem, the study consists of four (4) parts, namely: 1) Quantitative analyses on the program intended learning outcomes and course content through assessment of the Dean, the Department Chairperson, the Faculty Members, the Alumni, representing the various pharmaceutical areas; and 2) Quantitative analyses on the program intended outcomes and course content through assessment of the learning activities of the graduating students; and 3) Qualitative and quantitative analysis of the open-ended questions on the graduate attributes, coherence of the current curriculum, Pharmacy courses, internship, elective clerkships, and other concerns (strengths, weaknesses, problems, opportunities and threats) of the present curriculum; and 4) Enhancement or development and revisions to be adopted in the the proposed B.S. Pharmacy program.

\section{Theoretical framework}

The aspects of Pharmacy Curriculum planning can be presented in Figure 1, which shows how they relate and influence one another. The study will first consider mission-vision of the institution, also known as institutional intended learning outcomes (IILO) or competencies of an ideal graduate which will lead to specification of Department of Pharmacy goals or program intended learning outcomes (PILO). The PILO will then be formulated under the following main areas or competencies: academic excellence, leadership and teamwork, critical thinking and problem solving skills, productivity and accountability, social and ethical responsibilities, communication and relational skills, and global engagement.

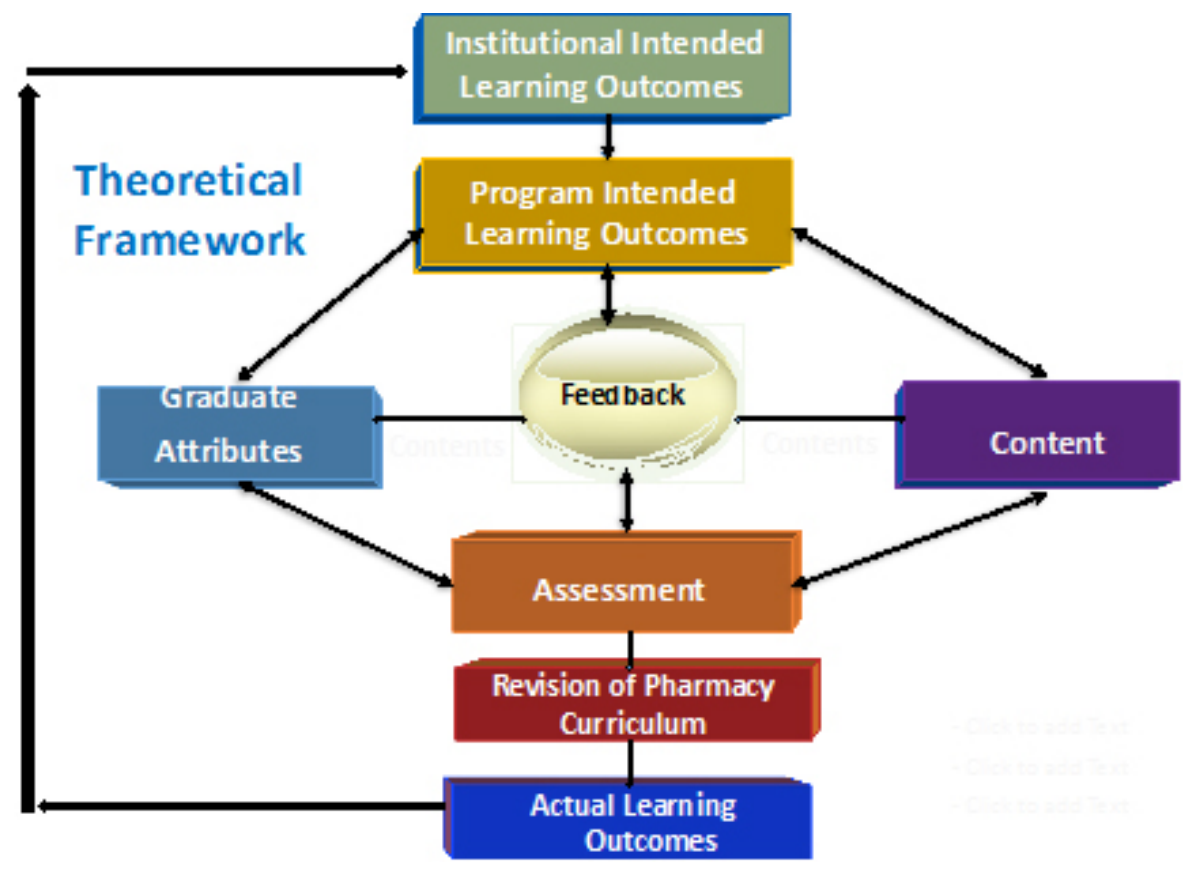

Figure 1. Curriculum planning model illustrating outcomes-based approach to pharmacy curriculum development 
In addition to these professionally related capabilities, recognition of graduates' broader range of competencies ( $21^{\text {st }}$ century skills) is needed, such as critical thinking, decisionmaking, life and career, problem-solving skills, communication skills, personal and social responsibility, creativity, communication, collaboration, information and communications technology, information literacy and citizenship.

The next task is to design content, learning activities, and assessment. The curriculumplanning model will use feedback as the central element. The central part of the model might be compared to the interaction model of curriculum development, one of those commonly cited in curriculum texts ${ }^{3}$. This consists of four (4) essential elements, namely, objectives, content, activities, and evaluation, with each element permitted to interact with the others. In the interactive model of curriculum development, the link or interrelatedness of central elements implies that the order of dealing with each element is not predetermined. More so, this is intended to emphasize the importance of achieving consistency between the curriculum elements in the model. For a curriculum to succeed in achieving the intended learning outcomes, each element needs to be related to the other elements in a coherent manner ${ }^{4}$.

It also features a feedback loop and interaction between the components. This implies that assessment and curriculum refinement are ongoing processes. Feedback needs to be sought from the stakeholders to inform regular improvements to the curriculum such as: surveys of the Dean, Department Chairperson, Faculty Members, graduating Pharmacy students, Alumni representing the various pharmaceutical sectors; evaluation of the outcomes of the accreditation; and assessment of the actual and desired learning outcomes of the students. The actual learning outcomes will be identified. Henceforth, enhancement or development of a revised B.S. Pharmacy program will take precedence. use

\section{RESEARCH DESIGN}

The quantitative to triangulation research design method is used in the study. Triangu- lation method is a qualitative method that checks and establishes validity by analyzing the research question from multiple perspectives in order to arrive at consistency across data sources or approaches.

Therefore, this study gathers data and information on prevailing policies, practices, study programs, and course offerings of Bachelor of Science in Pharmacy of the University of Santo Tomas with a view to propose a five-year Bachelor of Science in Pharmacy program intended to develop continuous learning among professional pharmacists, and in doing so, they are able to meet the demands of the dynamic work settings and the regulatory requirements related to professional practice ${ }^{5}$.

The Ethics and Review Board of the Faculty Pharmacy evaluated and approved the dissertation proposal prior to the distribution of the questionnaire to the administrators, faculty members, alumni, and graduating students.

Multi-aspect questionnaires are used as instruments for data gathering where informal random and open-ended questions were answered by the respondents. The study focused on the current four (4) year curriculum of B.S. Pharmacy program of University of Santo Tomas. The timeframe of the study is the school year 20152016.

\section{Population and study sampling}

The total number of respondents is three hundred one (301) consisting of four (4) groups namely: 1) two (2) Administrators (Dean and Department of Pharmacy Chairperson); 2) twenty-two (22) B.S. Pharmacy faculty members; 3) two hundred fifty seven (257) graduating B.S. Pharmacy students; and 4) twenty (20) B.S. Pharmacy alumni/alumna (four (4) from hospital pharmacy, three (3) from community pharmacy, eight (8) from pharmaceutical industry and five (5) from FDA).

The graduating B.S. Pharmacy students were further clustered based on their sections (A to F). The study focuses on the current four (4) year curriculum of B.S. Pharmacy program of University of Santo Tomas. 


\section{Survey questionnaire}

The survey questionnaire for the B.S. Pharmacy Graduating Students consists of two (2) parts. The first part pertains to the areas of concern perceived to be significant in the Program Intended Learning Outcomes of the current B.S. Pharmacy Curriculum through assessment of the learning activities or competencies of the graduating students ${ }^{4}$. It consisted of fifty (50) items of which six (6) referred to academic excellence or professional knowledge, four (4) to leadership and teamwork, seven (7) to critical thinking, ten (10) to productivity and accountability, seven (7) to social and ethical responsibility, twelve (12) to communication and relational skills, and four (4) to global engagement.

The second part are open ended questions on current Pharmacy program concerning: 1) Graduate attributes ( $21^{\text {st }}$ century skills) requiring enhancement such as creativity, problemsolving, critical thinking, decision-making, collaboration, communication, information and communication technology, information literacy, citizenship, life and career, and personal and social responsibility; 2) Graduate attributes the graduating students suggest have to be added; 3) Coherence of Pharmacy Curriculum such as: course-alignment, course-sequence and courseintegration, appropriate placement of pre-requisite/ co-requisite course and course-preparedness; 4) Pharmacy Courses the graduating students suggest have to be added; 5) Proposed Electives clerkships in the curriculum; 6) Proposed revisions in the curriculum; 7) The strengths, weaknesses, opportunities and threats of the present curriculum.

The survey questionnaire for the Administrators (Dean and Department Chairperson), B.S. Pharmacy Faculty Members and the B.S. Pharmacy Alumni representing the various pharmaceutical sectors (hospital pharmacy, community pharmacy, pharmaceutical industry and FDA) likewise consists of two (2) parts.

The first part of the assessment is on the areas of concern perceived to be significant in the Program Intended Learning Outcomes of the current B.S. Pharmacy Curriculum. It consisted of twelve (12) items of which six (6) referred to academic excellence or professional knowledge and one (1) each for leadership and teamwork, critical thinking, productivity and accountability, social and ethical responsibility, communication and relational skills, and global engagement.

On the other hand, the second part of the questionnaire consists of open-ended questions on the current Pharmacy Program that are to be completed by the Administrators, Faculty Members and Alumni. Their responses would be an important component of the data - the perceptions on the program intended learning outcomes. These additional questions include: a) Pharmacy course/s to be removed or modified; b) coherence of curriculum concerning prerequisites/co-requisites, number of units per professional lecture courses only, professional lecture with laboratory and total number of units for each semester per year level; c) duration of Pharmacy Internship; and c) their day-to-day concerns on the courses/work handled.

The objective of the first part of the survey is to determine if the program intended learning outcomes have been achieved in the current curriculum. For the second part of the assessment, respondents' feedback will identify the needs or the gaps of the existing curriculum from the graduate attributes, coherence of existing curriculum, Pharmacy courses, internship, elective clerkships, courses to be removed or modified, proposed revisions in the curriculum and to the strengths, weaknesses, opportunities, and threats of the present curriculum.

\section{Statistical treatment and analysis of data}

The respondents' perceptions on the program intended learning outcomes of the current B.S. Pharmacy Curriculum were rated, using Likert-type scales. The frequency of High, Moderate and Low Significance Rating from each group and section cluster were taken. Kendall's tau b test was used to determine if there was a significant difference on the perspective of each group, as well as the student section cluster. A p-value $<0.05$ means a difference in the responses of the groups and section clusters. 
All statistical treatments and analyses were done using SPSS version $7.0^{6}$. Percentage was used to determine frequencies of given variables ${ }^{7}$.

\section{RESULTS AND DISCUSSION}

\section{Assessment of components of program intended learning outcomes}

On the overall assessment by the graduating students on the contribution of the current curriculum to the achievement of the components of the Program Intended Learning Outcomes (PILO) based from their learning activities/outcomes, high Significance is given to "Leadership \& Teamwork" and "Social \& Ethical Responsibility". Moderate to High Significance is given to "Academic Excellence", "Critical Thinking", "Productivity and Accountability", "Communications \& Relational Skills" and "Global Engagement".

The students gave a mean overall assessment of high significance. The results reveal that the existing curriculum has greatly contributed in achieving the components of the Program Intended Learning Outcomes (PILO) to the B.S. Pharmacy graduating students. Though appropriate enhancement should be given to those components that were given a rating of moderate to high significance such as: Academic Excellence, Critical Thinking, Productivity and Accountability, Communications \& Relational Skills and Global Engagement.

On the overall assessment given by Stakeholders on the contribution of the curriculum to the overall achievement of PILO (Table 1), high significance or $52.5 \%$ overall rating is given by the Stakeholders to the components of PILO. An in-depth analysis of the outcome of the evaluation (Table 2) based on the ratings given to the different competencies of the PILO shows that high significance is given to "Social and Ethical Responsibility" (81.1\%), "Communication \& Relational Skills" (70.8\%), "Leadership and Teamwork" (69.8\%), "Productivity and Accountability" (60.8\%). Moderate to High Significance is given to "Critical Thinking" (54.8\%), "Academic Excellence" (52.5\%), and "Global Engagement" (46.5\%). Thus, appropriate enhancement should be given to these competencies of PILO.

Table 1. Assessment given by stakeholders on the contribution of the curriculum to the overall achievement of PILO

\begin{tabular}{lcccccccccc}
\hline \multirow{2}{*}{ Significance } & \multicolumn{2}{c}{ Students } & \multicolumn{2}{c}{ Administrator } & \multicolumn{2}{c}{ Faculty } & \multicolumn{2}{c}{ Alumni } & \multicolumn{2}{c}{ Total } \\
\cline { 2 - 12 } & $\mathrm{n}$ & $\%$ & $\mathrm{n}$ & $\%$ & $\mathrm{n}$ & $\%$ & $\mathrm{n}$ & $\%$ & $\mathrm{n}$ & $\%$ \\
\hline High & 125 & 48.6 & 2 & 100.0 & 18 & 81.8 & 13 & 65.0 & 158 & 52.5 \\
Moderate & 130 & 50.6 & 0 & 0.0 & 4 & 18.2 & 7 & 35.0 & 141 & 46.8 \\
Low & 2 & 0.8 & 0 & 0.0 & 0 & 0.0 & 0 & 0.0 & 2 & 0.7 \\
Total & 257 & 626.8 & 2 & 100.0 & 22 & 100.0 & 20 & 100.0 & 301 & 100.0 \\
\hline
\end{tabular}

Table 2. Summary of the individual assessment of the program intended learning outcomes

\begin{tabular}{lccc}
\hline $\begin{array}{c}\text { Program Intended Learning Outcomes } \\
\text { (Competencies of an Ideal Graduate) }\end{array}$ & High & Moderate & Low \\
\hline Social \& Ethical Responsibility & 81.1 & 18.3 & 0.7 \\
Communication \& Relational Skills & 70.8 & 28.6 & 0.7 \\
Leadership \& Teamwork & 69.8 & 29.2 & 1.0 \\
Productivity \& Accountability & 60.8 & 38.9 & 0.3 \\
Critical Thinking, Research and Problem Solving & 54.8 & 44.2 & 1.0 \\
Academic Excellence & 52.5 & 46.8 & 0.7 \\
Global Engagement & 46.5 & 48.8 & 4.7 \\
\hline
\end{tabular}


The results imply that the existing curriculum has made a significant contribution in achieving the competencies of the Program Intended Learning Outcomes (PILO) to the B.S. Pharmacy graduating students and to the Alumni or graduates.

\section{Open-ended questions}

\section{Assessment on the graduate attributes (21 ${ }^{\text {st }}$ century skills)}

The overall assessment given by Stakeholders on graduate attributes $\left(21^{\text {st }}\right.$ century skills) is illustrated in .Table 3. From the calculated mean percentages given by each respondent and the different groups, the graduate attributes were ranked from the attribute/competency most likely to be augmented to the least. Almost half of the respondents thought that their Critical Thinking skills (49.5\%) have to be enhanced. One third of the respondents voted for DecisionMaking (37.2\%). Almost one fourth have chosen Problem-Solving (23.5\%). The least voted among the graduate attributes are: Communication (22.5\%), Life and Career (21.9\%), Personal and Social Responsibility (20.9\%), Collaboration (18.6\%), Creativity (18.2\%), Information \& Communications Technology (14.2\%), Information Literacy (9.6\%), and Citizenship (6.0\%).

Table 3. Overall assessment given by stakeholders on graduate attributes ( $21^{\text {st }}$ century skills) requiring enhancement

\begin{tabular}{|c|c|c|c|c|c|c|c|c|c|c|}
\hline \multirow{3}{*}{ Graduate Attributes } & \multicolumn{8}{|c|}{ Respondents } & & \\
\hline & \multicolumn{2}{|c|}{ Administrators } & \multicolumn{2}{|c|}{ Faculty } & \multicolumn{2}{|c|}{ Alumni } & \multicolumn{2}{|c|}{$\begin{array}{c}\text { Graduating } \\
\text { Students }\end{array}$} & \multicolumn{2}{|c|}{ Total } \\
\hline & $\mathrm{f}$ & $\%$ & $\mathrm{f}$ & $\%$ & $\mathrm{f}$ & $\%$ & $\mathrm{f}$ & $\%$ & $\mathrm{f}$ & $\%$ \\
\hline a. Critical Thinking & 1 & 50.0 & 14 & 63.4 & 11 & 55.0 & 124 & 48.2 & 150 & 49.8 \\
\hline b. Decision-Making & 1 & 50.0 & 12 & 54.5 & 9 & 45.0 & 90 & 35.0 & 112 & 37.2 \\
\hline c. Problem-Solving & 1 & 50.0 & 13 & 59.0 & 9 & 45.0 & 48 & 18.6 & 71 & 23.5 \\
\hline d. Communication & 1 & 50.0 & 15 & 68.2 & 9 & 45.0 & 43 & 16.7 & 68 & 22.5 \\
\hline e. Life \& Career & 1 & 50.0 & 5 & 22.7 & 8 & 40.0 & 52 & 20.2 & 66 & 21.9 \\
\hline \multicolumn{11}{|l|}{ f. Personal \& Social } \\
\hline Responsibility & 2 & 100.0 & 12 & 54.5 & 5 & 25.0 & 44 & 17.1 & 63 & 20.9 \\
\hline g. Collaboration & 1 & 50.0 & 7 & 31.8 & 7 & 35.0 & 41 & 15.9 & 56 & 18.6 \\
\hline h. Creativity & 1 & 50.0 & 7 & 31.8 & 4 & 20.0 & 43 & 16.7 & 55 & 18.2 \\
\hline \multicolumn{11}{|l|}{ i. Information \& } \\
\hline \multicolumn{11}{|l|}{ Communications } \\
\hline Technology & 1 & 50.0 & 5 & 22.7 & 7 & 35.0 & 30 & 11.6 & 43 & 14.2 \\
\hline j. Information Literacy & 1 & 50.0 & 5 & 22.7 & 4 & 20.0 & 19 & 7.4 & 29 & 9.6 \\
\hline k. Citizenship & 2 & 100.0 & 5 & 22.7 & 1 & 5.0 & 9 & 3.5 & 17 & 6.0 \\
\hline
\end{tabular}

Integrating the graduate attributes $\left(21^{\text {st }}\right.$ century skills) to the Institutional Intended Learning Outcomes or competencies of the PILO (Table 4), the top three (3) graduate attributes chosen: "Critical Thinking” (49.5\%), "Decision-Making" (37.2\%), and "Problem-
Solving" (23.5\%) are characterized in Critical Thinking, Research and Problem Solving Skills of the PILO. They can also be categorized under Academic Excellence. The fourth most chosen graduate attribute is "Communication" (22.5\%), which can be classified under Global Engagement 
and Communication and Relational Skills. The assessment of the PILO is consistent with the results on the evaluation of the graduate attributes ( $21^{\text {st }}$ Century skills). Thus, these competencies of the PILO: a) Critical thinking, Researh and Problem Solving Skill, b) Academic Excellence, c) Global Engagement, and d) Communication and Relational Skills should be given greater enrichment or concern in the Pharmacy Curriculum.

The suggested graduate attributes by the Faculty and Alumni that are essential for inclusion are: research-orientedness, life-long learning, operational excellence and customer service skills, work ethics and values, and advocacies of environment.

Table 4. Integration of the graduate attributes ( $21^{\text {st }}$ century skills) to the institutional intended learning outcomes/competencies of program intended learning outcomes

\begin{tabular}{ll}
\hline \multicolumn{1}{c}{ PILO } & \multicolumn{1}{c}{ Graduate Attributes (21 ${ }^{\text {ST }}$ century skills $)$} \\
\hline Academic Excellence & $\begin{array}{l}\text { Foundation of Pharmacy Courses, Decision- } \\
\text { Making, Learning, Creativity, Problem-Solving } \\
\text { citizenship, life \& career, collaboration }\end{array}$ \\
Leadership and Teamwork & $\begin{array}{l}\text { creativity, problem-solving, decision making, } \\
\text { Critical Thinking, Research and Problem }\end{array}$ \\
Solving Skills & communication \& collaboration, life-long \\
Productivity and Accountability & learning, research \\
Social and Ethical Responsibility & personal \& social responsibility \\
Communication and Relational Skills & collaboration, information literacy, ICT, \\
& communication \\
Global Engagement & research, collaboration, communication \\
\hline
\end{tabular}

\section{Assessment on coherence of pharmacy curriculum}

The students' assessment on Coherence of Pharmacy Curriculum affirms the "coursealignment to the PILO" $(85.6 \%)$, "appropriate placement of pre-requisite/co-requisite courses" $(96.5 \%)$, "preparedness of students for each new course taken because of previous knowledge acquired" (92.2\%), “course sequence appropriateness" (85.2\%), and "proper course integration" (92.6\%).

The assessment of Administrators, Faculty, and Alumni to the Coherence of the current curriculum (Table 5) reveals that there is: "course-alignment to the PILO" $(88.6 \%)$, "course-sequence appropriateness" (75.0\%), "course-integration" (84.1\%), "Pre-requisite/ co-requisite courses are appropriately placed" $(84.1 \%)$, and "they are amenable to the number of units per professional lecture courses only"
(75.0\%), "number of units per professional lecture with laboratory" (72.7\%) and "total number of units for the courses are suitable for each semester per year level" (72.7\%).

On course-alignment, some alumni suggested that courses are to be aligned with the Pharmacy practice and are not limited with academic settings. Greater concentration or weight should be given to the major and professional courses, including clinical trials and research.

For the Faculty on course-alignment, grouping of the courses should be undertaken. Moreover, all goals and objectives (PILO) must be aligned with the learning activities given to students. Research output should also be given outmost importance.

On course-sequence, course code must be revised such that they are named in a chronological order. Some courses need to be 
taken as a pre-requisite for another course. A brief but detailed description on the different courses should be provided, so that the students are aware of the nature of the courses included in the curriculum.

Suggestions from the alumni include course-integration, noting provisions for actual practice and learning experiences in the community, hospital, clinical, and manufacturing pharmacies during the last term of the fourth year. The curriculum must also include development of more soft skills and leadership skills and management related courses. Another suggestion noted the need for student development on multifaceted expertise and a grasp of interrelationships in the real world that brings together diverse disciplines in a comprehensive manner.

Table 5. Overall assessment given by the administrators, faculty members and alumni on the coherence of curriculum

\begin{tabular}{|c|c|c|c|c|c|c|c|c|}
\hline \multirow{3}{*}{$\begin{array}{c}\text { Coherence of Pharmacy } \\
\text { Curriculum }\end{array}$} & \multicolumn{6}{|c|}{ Participants } & & \\
\hline & \multicolumn{2}{|c|}{ Administrators } & \multicolumn{2}{|c|}{ Faculty } & \multicolumn{2}{|c|}{ Alumni } & \multicolumn{2}{|c|}{ Total } \\
\hline & $\mathrm{f}$ & $\%$ & $f$ & $\%$ & $\mathrm{f}$ & $\%$ & $\mathrm{f}$ & $\%$ \\
\hline \multicolumn{9}{|l|}{ A. Course-alignment to the } \\
\hline $\begin{array}{l}\text { Program Intended Learning } \\
\text { Outcomes }\end{array}$ & 2 & 100.0 & 20 & 90.9 & 17 & 85.0 & 39 & 88.6 \\
\hline $\begin{array}{l}\text { B. Course-sequence } \\
\text { appropriateness }\end{array}$ & 2 & 100.0 & 14 & 63.4 & 17 & 85.0 & 33 & 75.0 \\
\hline C. Course-integration & 2 & 100.0 & 19 & $86.3 \%$ & 16 & 80.0 & 37 & 84.1 \\
\hline $\begin{array}{l}\text { D. Pre-requisite/co-requisite } \\
\text { courses appropriately placed }\end{array}$ & 1 & 50.0 & 19 & $86.3 \%$ & 17 & 85.0 & 37 & 84.1 \\
\hline $\begin{array}{l}\text { E. Number of units fitted for } \\
\text { each professional course }\end{array}$ & & & & & & & & \\
\hline $\begin{array}{l}\text { 1. Number of units per } \\
\text { professional lecture } \\
\text { courses only }\end{array}$ & 1 & 50.0 & 15 & $72.7 \%$ & 17 & 85.0 & 33 & 75.0 \\
\hline $\begin{array}{l}\text { 2. Number of units per } \\
\text { professional lecture } \\
\text { with laboratory }\end{array}$ & 1 & 50.0 & 16 & $72.7 \%$ & 15 & 75.0 & 32 & 72.7 \\
\hline $\begin{array}{l}\text { F. Total number of units for the } \\
\text { courses suitable for each } \\
\text { semester per year level }\end{array}$ & 2 & $100 \%$ & 16 & $72.7 \%$ & 14 & 80.0 & 32 & 72.7 \\
\hline
\end{tabular}

For the number of units per professional lecture courses, the faculty suggests the number of units for Research and Thesis Writing 1 has to be increased. Maximum units requirement should be given for a specific program to develop the needed learning competencies of the students and achieve threshold standards.
The Alumni suggested a change in the number of units per professional lecture with laboratory, giving due focus on laboratory skills of the students to increase their competence and national and global competitiveness. Another Alumni commented the need to review the number of units between the lecture and laboratory 
as the students learn more from their laboratory experience and the weight or impact of the laboratory units should likewise be appropriately reflected.

A faculty suggested that aside from the total number of units, the academic load and the allocation of the number of units per term for each year level should be assessed. One suggests that the last term of the fourth (4th) year should be focused on course audit as other courses given alongside this are not given the same attention and focus due to the intensity and the comprehensive nature of the course audit.

From the remarks or comments given, there should be changes or modifications on the courses, distribution of schedules, time, learning activities and the academic load in the current curriculum. The students should be exposed and involved in actual learning experiences. Courses should include the actual practice of Pharmacy and are not limited to the acquisition of theories in academic settings. The curriculum also has to be aligned to other countries' curriculum.

\section{Assessment on courses suggested to be add- ed in the current curriculum}

On the overall assessment given by Stakeholders on courses suggested to be added in the current curriculum (Table 6), the responses by the Stakeholders were not the same. The students gave higher ratings than the Administrators, Faculty, and Alumni.

Table 6. Overall assessment given by stakeholders on courses suggested to be added in the current curriculum

\begin{tabular}{|c|c|c|c|c|c|c|c|c|c|c|}
\hline \multirow{3}{*}{ Courses Suggested } & \multicolumn{8}{|c|}{ Respondents } & & \\
\hline & \multicolumn{2}{|c|}{ Administrators } & \multicolumn{2}{|c|}{ Faculty } & \multicolumn{2}{|c|}{ Alumni } & \multicolumn{2}{|c|}{$\begin{array}{l}\text { Graduating } \\
\text { Students }\end{array}$} & \multicolumn{2}{|c|}{ Total } \\
\hline & $\mathrm{f}$ & $\%$ & $\mathrm{f}$ & $\%$ & f & $\%$ & f & $\%$ & f & $\%$ \\
\hline a. Pharmacotherapeutics & 1 & 50.0 & 13 & 59.1 & 10 & 50.0 & 250 & 97.2 & 274 & 91.0 \\
\hline $\begin{array}{l}\text { b. Integrative Medicine } \\
\text { (Complementary \& } \\
\text { Alternative Medicine) }\end{array}$ & 1 & 50.0 & 11 & 50.0 & 7 & 35.0 & 248 & 96.5 & 267 & 88.7 \\
\hline c. Drug Delivery Systems & 1 & 50.0 & 11 & 50.0 & 8 & 40.0 & 242 & 94.2 & 262 & 87.0 \\
\hline d. Drug Discovery \& Development & 1 & 50.0 & 10 & 45.5 & 10 & 50.0 & 235 & 91.4 & 256 & 85.0 \\
\hline e. Cosmetic Product Formulation & 2 & 100.0 & 12 & 54.5 & 7 & 35.0 & 223 & 86.8 & 244 & 81.1 \\
\hline f. Pharmacoepidemiology & 0 & 0.0 & 10 & 45.5 & 2 & 10.0 & 213 & 82.3 & 225 & 74.8 \\
\hline g. Regulatory Pharmacy & 1 & 50.0 & 17 & 77.3 & 15 & 75.0 & 190 & 73.9 & 223 & 74.1 \\
\hline h. Pharmacoeconomics & 0 & 0.0 & 10 & 45.5 & 6 & 30.0 & 199 & 77.4 & 215 & 71.4 \\
\hline i. Immunology \& Hematology & 0 & 0.0 & 9 & 40.9 & 4 & 20.0 & 200 & 77.8 & 213 & 70.8 \\
\hline $\begin{array}{l}\text { j. Pharmacy Business Management } \\
\text { (with Accounting) }\end{array}$ & 1 & 50.0 & 17 & 77.3 & 11 & 55.0 & 166 & 64.6 & 195 & 64.8 \\
\hline
\end{tabular}

From the results, it implies that the stakeholders favor the inclusion of the courses suggested in the existing Pharmacy Curriculum such as: "Integrative Medicine" (88.7\%), "Drug Delivery Systems” (87.0\%), "Drug Discovery and Development" (85\%), "Cosmetic Product Formulation" (81.1\%), "Pharmacoepidemiology" (74.8\%), "Regulatory Pharmacy” (74.1\%), "Pharmacoeconomics" (71.4\%), "Immunology and Hematology" (70.8\%), and "Pharmacy 
Business Management" (64.8\%). This implies that the stakeholders favor the addition of these courses in the proposed Pharmacy Curriculum.

Other courses suggested by the Students are: Molecular Biology, Biotechnology, Entrepreneurship and Oncology; to separate Physiology from Human Anatomy and Microbiology from Parasitology. The Alumni recommends in-depth course on Current Good Manufacturing Practice (CGMP) and standards used by the national regulatory agency. For the Administrator, they see the need to add Foreign language courses. Meanwhile, the faculty members suggested Physical Chemistry, Radiopharmacy, Drug modelling through computer application, Ethnopharmacology, Social Pharmacy, Parenteral Therapy, and Zoology.

For the removal or modification of course offerings, the students requested the separation of Human Physiology and Pathophysiology from Human Anatomy; the transfer of some courses from third year second term to third year first term, such as Pharmacognosy, which includes updating of its activities, and Course Audit to be given on separate time. Students also see the need for more student involvement, patient exposure, actual learning experiences, and concrete and interactive learning outcomes. Actual cases should also be provided. Clerkship should also be included under clinical courses. On the other hand, according to the alumni, Pharmacognosy units need to be increased. In addition, Pharmacognosy, Plant Chemistry and other Pharmaceutical Chemistry courses need to be simplified. For the Faculty, they recommend the modification or improvement of Pharmacy Informatics; Organic Medicinals Laboratory, and Pharmacognosy. Moreover, Botany must be more pharmaceutical in approach. Other faculty recommendations on course offerings include the separation of Pharmacognosy and Plant Chemistry from Philippine Medicinal Plants, the combination of Pharmaceutical Jurisprudence and Healthcare Ethics; and the alignment of the current curriculum with clinical practice, which includes further specialization on the field.

\section{Assessment on the extent of pharmacy internship}

The response of the respondents from different groups of stakeholders is homogenous in the assessment on lengthening the duration of Pharmacy Internship. The low significance rating implies the disapproval of the administrators, faculty, and the alumni of the increase on the number of hours of Pharmacy Internship.

For some respondents who affirmed the lengthening of the Pharmacy Internship, an Alumna remarked, as proposed in the new law, the 960 hours internship will be increased to 1,200 hours. In this case, students will be more immersed at real-life situation. An Alumnus suggested to lessen didactic sessions and lengthen clerkship hours. A Faculty suggests that if the Curriculum will be increased to five (5) years, the whole fifth year should be dedicated to the internship program.

For greater exposure and experience to realities of work, there is indeed a need to prolong the duration for the three (3) areas of Pharmacy Internship such as: Community Pharmacy, Hospital Pharmacy, and Pharmaceutical Industry. Two (2) new areas of Pharmacy Internship will be added, namely, Institutional Internship and Social and Administrative Internship, which shall provide students with an intense practice on the different fields of Pharmacy. This will serve as the simulation of the actual Pharmacy practice.

\section{Assessment on the suggested elective clerkships}

On the overall assessment given by Stakeholders on the suggested elective clerkships in the Pharmacy Curriculum (Table 7) the mean high ratings are due to the scores given by the students to all the Elective Clerkships such as: "Infectious Disease" (86.4\%), "Research" (86.4\%), "Outpatient Practice" (85.0\%), "International" (84.4\%), "Geriatrics" (83.0\%), "Administration" (81.7\%), and "Academic" (79.7\%). The responses of the alumni, administrators, and alumni are homogenous. The three (3) groups gave low ratings, which show their disapproval of incorporating elective clerkships in the curriculum. 
Table 7. Overall assessment given by stakeholders on the suggested elective clerkships in the pharmacy Curriculum

\begin{tabular}{|c|c|c|c|c|c|c|c|c|c|c|}
\hline \multirow{3}{*}{ Elective Clerkships } & \multicolumn{8}{|c|}{ Participants } & & \\
\hline & \multicolumn{2}{|c|}{ Administrators } & \multicolumn{2}{|c|}{ Faculty } & \multicolumn{2}{|c|}{ Alumni } & \multicolumn{2}{|c|}{$\begin{array}{c}\text { Graduating } \\
\text { Students }\end{array}$} & \multicolumn{2}{|c|}{ Total } \\
\hline & $\mathrm{f}$ & $\%$ & $\mathrm{f}$ & $\%$ & $\mathrm{f}$ & $\%$ & $f$ & $\%$ & $f$ & $\%$ \\
\hline a. Infectious Disease & 0 & 0.0 & 8 & 36.4 & 5 & 25.0 & 247 & 96.1 & 260 & 86.4 \\
\hline b. Research & 0 & 0.0 & 9 & 40.9 & 9 & 45.0 & 242 & 94.2 & 260 & 86.4 \\
\hline c. Outpatient Practice & 0 & 0.0 & 8 & 36.4 & 5 & 25.0 & 243 & 94.6 & 256 & 85.0 \\
\hline d. International & 0 & 0.0 & 7 & 31.8 & 4 & $20 \%$ & 243 & 94.6 & 254 & 84.4 \\
\hline e. Geriatrics & 0 & 0.0 & 5 & 22.7 & 2 & 10.0 & 243 & 94.6 & 250 & 83.0 \\
\hline f. Administration & 0 & 0.0 & 12 & 54.5 & 5 & 25.0 & 228 & 88.7 & 246 & 81.7 \\
\hline g. Academic & 0 & 0.0 & 3 & 13.6 & 2 & 10.0 & 235 & 91.4 & 240 & 79.7 \\
\hline
\end{tabular}

With the suggestion of some stakeholders that the students must be able to develop multifaceted expertise and be able to grasp the importance of interrelationship in the real world that will bring together diverse disciplines in a comprehensive manner; thus these elective clerkships must be integrated in the Pharmacy Curriculum. Another reason for the inclusion is for experiential learning and likewise alignment of the current curriculum with the prescribed curriculum of other countries.

\section{Proposed revisions by the students in the existing curriculum}

On the overall assessment of Students on proposedrevisions in the currentcurriculum (Table 8), high significance ratings were given. This proposes the revisions on the following: improvements on instructional resources (facilities, equipment, instrument and laboratories); updating of textbooks and references; "foster innovative methodologies of instruction" (97.7\%), “develop more linkages" (97.7\%), "greater exposure to realities of work" (practicum and electives), and to "enhance research and extension activities" (95.7\%).

Other revisions suggested by the students include: collaboration with international universities; training of students in the real world (aside from internship); wider and better choices for sites of internships; provisions for genuine support for students, which include support for their thesis research, giving them access to laboratories and equipment, providing them hands on training during courses (e.g., Clinical Pharmacy) and more effort in securing global linkages. The curriculum must be made aligned with the actual Philippine practice rather than producing workers to work abroad. Furthermore, it was proposed to offer a five-Year Curriculum of Bachelor of Science Pharmacy Program

\section{Concerns on the courses/worked handled by the alumni, administrators and faculty in relation to day-to-day teaching or work- ing responsibilities}

The following are concerns raised by the faculty members on the manner courses are handled in relation to the teaching: 1) The administrator stated the insufficient number of hours to cover the scope of the courses, the need for students' participation and their higher retention and application of the lessons learned in various practical settings; 2) The faculty conveyed the need to address the following: the practical application and relevance of the scope of the courses, the uniformity of lessons taught including teaching techniques and the extent and relevance of information to be covered, 
Table 8. Overall assessment of students from different sections on the proposed revisions in the current curriculum

\begin{tabular}{lcc}
\hline \multicolumn{1}{c}{ Proposed Revisions } & \multicolumn{2}{c}{ Total } \\
\cline { 2 - 3 } & $\mathrm{f}$ & $\%$ \\
\hline a. Instructional resources (facilities, equipment, & 253 & 98.4 \\
$\quad$ instrument \& lab.) & 252 & 98.1 \\
b. Updated textbooks \& references & 251 & 97.7 \\
c. Innovative methodologies of instruction & 251 & 97.7 \\
d.More linkages (community, hospital, manufacturing, & & 96.9 \\
$\quad$ schools - local \& international) & 249 & 95.7 \\
e. Exposure to realities of work (practicum \& electives) & 246 & \\
a. Research \& extension activities & &
\end{tabular}

the poor communicative skills of the students, and provisions for intense practice in the different fields of Pharmacy amongst students, and time distribution of topics/activities to maximize learning outcomes. The students' academic load should also be reviewed that should include avenues and activities to ensure their wholistic development. Consultations and updating with the alumni should be further maximized to identify courses that need emphasis and decongest course offerings that can be repetitive and unnecessary. Instruments/equipment for laboratories/research are expensive. Moreover, didactic style teaching should be lessened. Teachers' roles should not be limited to lecturers but instead must be viewed as lecturers who motivate students to work independently.

\section{Strengths, weaknesses, opportunities, and threats of the present curriculum}

On the strengths of the current Pharmacy Curriculum, the following are responses given by students. Students found the curriculum organized, well integrated and effectively planned, which provide them with adequate avenues to be hardworking, critical thinkers. They also find the curriculum able to shape them into becoming globally competitive professional pharmacists fully equipped with the knowledge. As it is outcomes based, students found opportunities for self-learning that encourage independence, such as research and other related academic pursuits.

According to the alumni, majority of the basic topic/knowledge tools for a general pharmacist are offered in the current curriculum. For them, the curriculum is able to establish a solid foundation among the students the practice of Pharmacy. Moreover, Pharmacy identity is embedded in each course; hence, it is a globally competitive curriculum.

One of the Administrators remarked that the UST BS Pharmacy Curriculum is updated in terms of pre-requisites and course order/ offering. For the Faculty, the current curriculum allows outcomes-based teaching and learning; therefore, students find and produce expected outcomes on their own. Utilization of laboratories is conducted to enhance the skills of the students. Research opportunities are provided for the students, which may help in the development/ refining of critical thinking skills. More importantly, the curriculum has comparable solid foundation.

The limitations of the program mentioned by the students are as follows: lack of real world exposure or practice, the lack of training of students on disease management, insufficient student time to fully accomplish all activities and academic responsibilities; the lack of new methods for research and laboratory equipment, the lack of avenues and opportunities 
for application of learned concepts and principles, the lack of collaboration with schools of Pharmacy nationwide, flood prone area, the use of outdated equipment, inadequate equipment which are inappropriate for researchers, and a condensed curriculum.

The alumni noted the following limitations of the degree program: limited exposure/ collaboration with other healthcare professionals and patients, no background on regulatory pharmacy; updating of relevant contents of courses that relate to local and global practice, the lack of real life scenarios to prepare students for actual practice, and not at par with the current Philippine set-up/practice.

According to the faculty, the present curriculum lacks social application/immersion, and research-orientedness. It is also not patient oriented, which needs further hospital-based training. Though it shows good foundation, it is somehow left behind as compared to the program offered in other universities outside the country. There are limited equipment appropriate for instrumentation. Further, teachers are not available to meet students or parents often enough. For them, there is a need to address the incomplete professional courses offered.

For the Faculty, they conveyed the lack of grants/funds. Also, internship is conducted every summer; however, the internship course is offered only on the succeeding semester after the actual internship. They also noted the lack of actual application of knowledge and availability of equipment. They also suggested the need for specialization among graduates to be globally competitive. Problems with internship regarding institution partnership need to be addressed. They also noted the need for more social and administrative outputs.

On the opportunities of the existing Pharmacy Curriculum, the alumni stated that the program offers career opportunities in the different fields of Pharmacy in the Philippines. For the Faculty, international and local collaborations are implemented but must be strengthened, which include collaborative researches (local or international) with in the agencies as part of student/faculty mobility program. The faculty also noted how the program gives students enough skills and knowledge needed in the current Philippine practice of Pharmacy. New faculty members are hired with new/creative ideas. The program provides internationalization that fosters free exchange of technology and information.

With regards to the threats of the current curriculum, a student remarked that with the constant global changes, the program offered seems to lag behind in terms of a global perspective despite its traditional effectiveness. For the Alumni, updated curriculum of pharmacy profession based on international standards must always be aligned with UST curriculum; "other options," and "schedule" for professionals with relevant expertise will be a major barrier to be solved, and it serves as a stepping stone of students to go abroad since applicability to local setting is evident.

For the Faculty, the threats include the impact of K-12 and new Pharmacy Bill. They also noted that other universities offer the same specialization and strength in social action. Also, other schools offering a more extensive curriculum. Newly hired faculty members may struggle in terms of content mastery and teaching strategies. Other threats the faculty has noted include new trends in professional practice and challenges of globalization; from healthcare practice/pharmacy practice/professional education, the new curriculum that will be released by CHED, innovations in the healthcare system, new practices in pharmacy, and healthcare demands. Further, drug testing and assay in industry might be given to chemists, so it is necessary to strengthen our skills and the Pharmacy Law.

\section{Modified professional courses in the proposed five-year B.S. Pharmacy Curriculum}

The University of Santo Tomas (UST) BS Pharmacy Program has been granted Level IV Reaccreditation Status for five years (April 2014 to April 2019). With the achievement in the Pharmacy Board Examinations, the Commission on Higher Education (CHED) awarded the UST BS Pharmacy Program the Center of Excellence. 
This proves that the UST B.S. Pharmacy has demonstrated the highest degree or level of standards along the areas of instruction, research, and extension of its particular fields or courses ${ }^{8}$. The UST B.S. Pharmacy is an Autonomous HEI (by evaluation) that demonstrates exceptional institutional quality and enhancement consistent with their horizontal type through internal QA systems and demonstrate excellent program outcomes 9 .

Notwithstanding the outcomes of the Level IV reaccreditation visit, the assessment and feedback identified the needs or gaps in the current curriculum of the existing four-year BS Pharmacy Program. It was then concluded that three (3) major areas of revision were needed: (1) introduce students to the professional practice of pharmacy at the onset of their pharmacy education, (2) provide opportunities for students to practice what they learn in real-life environments, and (3) integrate related courses to reduce duplication of materials and increase relevance between subjects ${ }^{4}$.

With the results of the survey, the major and professional courses in the four-year curriculum of BS Pharmacy Degree Program are retained with some modifications. Table 9 shows the modified professional courses in the proposed new Pharmacy Curriculum.

The new guidelines, policies, and standards (GSP) of CHED for the BS Pharmacy program were consulted. Pharmacy curricula from various parts of the world, including the United States, United Kingdom, Canada, Australia, and ASEAN countries were also examined for alignment in the updating of courses and in ensuring students' global competitiveness.

Table 9. Modified professional courses in the proposed five-year BS Pharmacy Curriculum

\begin{tabular}{ll}
\hline \multicolumn{1}{c}{ Four -Year BS Pharmacy Curriculum } & \multicolumn{1}{c}{ Five - Year BS Pharmacy Curriculum } \\
\hline Human Anatomy, Physiology & Reorganized into: \\
\& Pathophysiology & a. Human Anatomy \\
& b. Human Physiology \& Pathophysiology \\
Principles of Pharmacy Administration \& & \\
Management I & Introduction to Pharmaceutical Management \\
& \& Leadership \\
Pharmaceutical Microbiology \& Parasitology & Pharmaceutical Microbiology \& Immunology \\
Pharmaceutical Biochemistry & Pharmaceutical Biochemistry \\
& and Molecular Biology \\
Dispensing \& Medication Counseling & Restructured into: \\
& a. Basic Dispensing (Dispensing Process, \\
& Reading \& Interpreting the Prescription \\
& and Other Medicine Orders) \\
& b. Dispensing \& Medication Safety \\
& c. Patient Medication Counseling \\
& Clinical Toxicology with Drug Abuse \\
& Rationalized into: \\
Clinical Toxicology & a. Basic Pharmaceutical Dosage Forms \\
Pharmaceutical Dosage Forms & b. Drug Delivery Systems \\
& c. Drug Discovery and Development \\
& d. Cosmetic Product Formulation \\
\hline &
\end{tabular}




\section{Proposed B.S. Pharmacy degree program reflecting an outcomes-based approach to curriculum development \\ The stakeholders' suggestions include the} integration of new related courses, lengthening of the existing curriculum from four (4) years into five (5) years, transfer of some courses offered in the first year, second year, and in the third year. It is also recommended that some of the courses be offered in the lower years, for the students to relate the knowledge acquired to other relevant Pharmacy courses (e.g., Pharmaceutical Management and Leadership, Pharmaceutical Marketing \& Entrepreneurship, and Pharmaceutical Informatics). Through students' suggestions of the inclusion of elective clerkship in the curriculum, opportunities for students to practice what they learn in real-life environment aside from their Pharmacy Internships are provided.

Table 10 shows the proposed five-year B.S. Pharmacy Degree Program reflecting an outcomes-based approach to curriculum development.

Table 10. Bachelor of Science in Pharmacy (B.S. Pharmacy) degree program reflecting an outcomesbased approach to curriculum development

\begin{tabular}{|c|c|c|}
\hline \multirow{2}{*}{ Course Title } & \multicolumn{2}{|c|}{ Units } \\
\hline & Term 1 & Term 2 \\
\hline \multicolumn{3}{|l|}{ Year 1} \\
\hline Introduction to Pharmacy/Perspective in Pharmacy & 3 & \\
\hline Pharmaceutical Botany with Taxonomy with Lab. & 5 & \\
\hline Chemistry \& Pharmacy of Inorganic Medicinals & 5 & \\
\hline with Qualitative Chemistry with Lab. & & \\
\hline Introduction to Pharmaceutical Care (Concept of Health & 3 & \\
\hline \multicolumn{3}{|l|}{ Care System) } \\
\hline Common Core Courses $* * *$ & 9 & \\
\hline Pharmaceutical Calculations & & 3 \\
\hline Human Anatomy with Laboratory* & & 5 \\
\hline Pharmaceutical Organic Chemistry with Lab. & & 5 \\
\hline Introduction to Pharmaceutical Management \& Leadership & & 3 \\
\hline Internship I: Community Pharmacy & & 2 \\
\hline Common Core Courses*** & & 9 \\
\hline Sub-total & 25 & 27 \\
\hline Special Term Community Pharmacy Internship (300 hours) & & \\
\hline \multicolumn{3}{|l|}{ Year 2} \\
\hline $\begin{array}{c}\text { Basic Dispensing (Dispensing Process, Reading \& Interpreting \& } \\
\text { the Prescription and Other Medicine Orders) with Lab }\end{array}$ & 4 & \\
\hline Human Physiology\& Pathophysiology with Lab. & 5 & \\
\hline $\begin{array}{l}\text { Pharmaceutical Analysis 1/Quality Control } 1 \text { with Lab. } \\
\text { (Quantitative Chemistry 1) }\end{array}$ & 4 & \\
\hline Pharmaceutical Marketing \& Entrepreneurship & 3 & \\
\hline Pharmaceutical Biochemistry and Molecular Biology with Lab. & 5 & \\
\hline Pharmacy Informatics with Lab. & 3 & \\
\hline
\end{tabular}


Table 10. Bachelor of Science in Pharmacy (B.S. Pharmacy) degree program reflecting an outcomesbased approach to curriculum development

\begin{tabular}{|c|c|c|}
\hline \multirow{2}{*}{ Course Title } & \multicolumn{2}{|c|}{ Units } \\
\hline & Term 1 & Term 2 \\
\hline Pharmaceutical Dosage Forms with Lab. & & 4 \\
\hline Pharmacy \& Chemistry of Organic Medicinals with Lab. & & 4 \\
\hline Pharmacognosy, with PMP \& Plant Chemistry with Lab. & & 5 \\
\hline Pharmaceutical Microbiology \& Immunology with Lab & & 5 \\
\hline Hospital Pharmacy with Interprofessional Approach & & 3 \\
\hline Internship II: Hospital Pharmacy & & 2 \\
\hline Subtotal & 24 & 23 \\
\hline Special Term Hospital Pharmacy Internship (300 hours) & & \\
\hline \multicolumn{3}{|l|}{ Year 3} \\
\hline Integrative Medicine (Complementary \& Alternative Medicine)* & 2 & \\
\hline Drug Delivery Systems* & 3 & \\
\hline $\begin{array}{l}\text { Pharmaceutical Analysis 2/Physical Pharmacy with Lab. } \\
\text { (Instrumental Methods of Analysis) }\end{array}$ & 4 & \\
\hline Public Health Pharmacy & 3 & \\
\hline Drug Discovery \& Development* & 2 & \\
\hline $\begin{array}{l}\text { Pharmaceutical Manufacturing \& CGMP (including validation) } \\
\text { with lab. }\end{array}$ & 5 & \\
\hline Pharmacology $1 \&$ Therapeutics & 4 & \\
\hline Cosmetic Product Formulation with Lab.* & & 4 \\
\hline Pharmacotherapy $1^{*}$ & & 4 \\
\hline Dispensing \& Medication Safety with Lab. & & 4 \\
\hline Pharmacy Business Management (with Accounting)* & & 2 \\
\hline Pharmacology II \& Therapeutics with Lab. & & 5 \\
\hline Biopharmaceutics \& Pharmacokinetics & & 3 \\
\hline Internship III: Industrial Pharmacy & & 2 \\
\hline Subtotal & 23 & 24 \\
\hline Special Term Industrial Pharmacy Internship (300 hours) & & \\
\hline \multicolumn{3}{|l|}{ Year 4} \\
\hline Pharmacotherapy $2 *$ & 4 & \\
\hline Patient Medication Counseling* & 3 & \\
\hline Drug Testing \& Assay with Instrumentation with Lab. & 4 & \\
\hline Pharmaceutical Toxicology \& Drug Abuse & 3 & \\
\hline Clinical Pharmacy (Assessment with Monitoring) with Lab. & 4 & \\
\hline
\end{tabular}


Table 10. Bachelor of Science in Pharmacy (B.S. Pharmacy) degree program reflecting an outcomesbased approach to curriculum development

\begin{tabular}{|c|c|c|}
\hline \multirow{2}{*}{ Course Title } & \multicolumn{2}{|c|}{ Units } \\
\hline & Term 1 & Term 2 \\
\hline Pharmacy Research Methods/RTW 1 & 1 & \\
\hline Pharmaceutical Statistics with Lab. & 3 & \\
\hline Academic Writing Skills/Technical Writing (Core) & 3 & \\
\hline Pharmaceutical Jurisprudence \& Ethics & & 3 \\
\hline Pharmacotherapy $3 *$ & & 4 \\
\hline Regulatory Pharmacy* & & 3 \\
\hline Health Technology Assessments \& Health Policy & & 2 \\
\hline Introduction to Pharmacoepidemiology* & & 3 \\
\hline Research \& Thesis Writing II with Lab. & & 3 \\
\hline Healthcare Ethics (Core) & & 3 \\
\hline Pharmacoeconomics * & & 3 \\
\hline Internship IV: Institutional and Social and Administrative Internship & & 2 \\
\hline Subtotal & 25 & 26 \\
\hline $\begin{array}{ll}\text { Special Term } & \text { Institutional Internship (120 hours)*; and } \\
& \text { Social and Administrative Internship (180 hours)* }\end{array}$ & & \\
\hline
\end{tabular}

Year 5

Term 1

Area of Concentration: Pharmacy Clerkship (500 hours) choice of:

Community Pharmacy Clerkship

Hospital Pharmacy Clerkship

Industrial Pharmacy Clerkship

And choice of one elective clerkship (300 hours)* in:

Clinical Pharmacy Clerkship: Infectious Diseases

Hospital Pharmacy Experience in International Country

Clinical Pharmacy Clerkship: Pediatric

Clinical Pharmacy: Outpatient Practice

Clinical Pharmacy: Geriatrics

Social Pharmacy: Administration

Institutional: Academic/Research

Term 2

Course Audit

\footnotetext{
*** Candidates are required to successfully complete six General Education Core/General Education Elective Courses (GPS CHED, 2016): Foreign Language, Math, Science \& Technology, Theology, Purposive Communication, Social Sciences \& Philosophy, Psychology

*New related courses integrated
} 
As suggested by the Alumni and students for more student involvement, patient exposure, actual learning experiences, and concrete learning outcomes, Pharmacy Internship is increased from 200 hours to 300 hours for Community, Hospital, and Industrial Pharmacy. There is also an added internship in Institutional for 120 hours and Social and Administrative for 180 hours.

In the fifth year, the students during the first term will practice in their chosen area of concentration/specialization (from 360 hours is increased to 500 hours) in accredited establishments, such as community, hospital, and the industry. As requested by all students, clerkship in real life scenarios is included as an elective in the Pharmacy Curriculum to prepare students in actual practice. The students may select one elective clerkship either in the practice of: Clinical Pharmacy such as a) infectious diseases, b) pediatric, c) outpatient practice, and d) geriatrics; Hospital Pharmacy in an International Country; Social Pharmacy on administrative training; and Institutional either in the academe or research. In the second term, the students will focus on course audit in preparation for the Pharmacy Licensure Examination.

\section{Learning outcomes of the proposed five-year} B.S. Pharmacy degree program reflecting an outcomes-based approach to curriculum development (GSP of CHED)

In the first year, students will manifest self-awareness; value pharmacy as a health profession; demonstrate understanding of basic human body structure, chemical, physical and biological principles relevant to pharmaceutical sciences; recognize important elements of the patient's heath profile; communicate effectively and develop interpersonal relationships; relate ethical principles to leadership and management in pharmacy; perform basic calculations necessary to Pharmacy practice; and provides healthcare information to various clients. Students will participate in introductory Pharmacy practice experiences in accredited community pharmacies, to provide an early exposure to the many facets of Pharmacy practice.
In the second year, the students will read and interpret prescription correctly; demonstrate knowledge and skills in identifying different dosage forms and drugs of biological origin and in ensuring the quality of medical and pharmaceutical products and services; demonstrate knowledge of the pharmacy and chemistry of pharmaceutical products; documents important information used in patient care and pharmacy operations; explain hospital organization/ committee functions, interpret and enter patient orders, fill unit-dose cassettes, and prepare intravenous admixtures; and apply marketing and entrepreneurial skills. Students will have an opportunity to undergo training in accredited hospital pharmacies to practice what they learn in a real-life environment.

In the third year, students will demonstrate analytical and problem-solving skills in dispensing medicines; will relate biological and physiological concepts to pharmacy (drugs, biotech products and diseases); will explain the drug development process, compounds and manufactures quality pharmaceutical products (including cosmetic products) according to official standards and regulatory guidelines; will relate biological and physiological concepts to pharmacy (drugs, biotech products and diseases); will apply public health tools, including population-based methods, strategies, and interventions in medication and relevant healthcare issues and policies; will apply public health tools, including population-based methods, strategies, and interventions in medication and relevant healthcare issues and policies; will explain alternative modalities; will critically evaluate scientific evidences for research and decision-making; and will apply business management skills. Students will practice in accredited pharmaceutical industries to hone their skills in the different areas of production for drugs.

In the fourth year, students will relate formulation, drug delivery, clinical effectiveness, and safety; will identify and resolve drug-related problems; will participate as a healthcare team member with demonstration of appropriate and effective inter-professional skills, mutual respect, 
and understanding of roles; will demonstrate continuous quality improvement techniques in the medication use process; will perform medication counseling; will apply standards and evidence-based best practices related to safe and effective medication use; will identify legal and regulatory issues that affect the practice of pharmacy; and will demonstrate sensitivity to ethical principles in professional and social contexts. Students will practice in accredited institutional and government health agencies for application of the knowledge and technical skills learned and acquired and for required exposure to real life experiences.

In the fifth year, the students during the first term will practice in their chosen area of concentration of accredited establishments, such as community, hospital, and industry. They will also select one elective clerkship either in the practice of: Clinical Pharmacy, Hospital Pharmacy, Institutional, and Social Pharmacy. In the second term, the students will focus on course audit in preparation for the Pharmacy Licensure Examination.

\section{CONCLUSIONS}

The UST Department of Pharmacy must continually refine and update as deemed to be appropriate the program intended learning outcomes to reflect state-of-the-art practice, develop a variety of educational experiences, assist students in maximally achieving these outcomes, and obtain and use valid, reliable, assessment data to make necessary changes in the curriculum. Pharmacy Alumni of various Pharmacy sectors, professional pharmaceutical associations, accrediting agencies (PACUCOA), Board of Pharmacy, CHED and school linkages (local and international) can fulfill an important role by assisting the Department of Pharmacy in their efforts to improve student learning, program outcomes, and modification or revision of the curriculum.

\section{REFERENCES}

1. Abueva, A. The implementation of the $\mathrm{K}-12$ program in the Philippine basic education curriculum. http://hubpages.com/ education/. Retrieved on January 28, 2016

2. Olds, K., Robertson, S. Towards harmonization of higher education in Southeast Asia. https:/www.insidehighered.com/blogs/ globalhighered/ towards harmonizationhigher-education-southeast-asia. Retrieved on January 28, 2016.

3. Brady, L., Kennedy, K. Curriculum construction. $5^{\text {th }}$ ed. Copyright @ Pearson Australia.

4. Ho, S. S., Kember, D. Instructional design and assessment, an outcomes-based approach to curriculum development in pharmacy. Am J Pharm Edu. 2009;73(1):Article 14.

5. Guile, D. Ahamed, F. Modernising the pharmacy curriculum published by the center for learning and life chances in knowledge economies and societies. Retrieved from http://www.llakes.org.

6. Norusis M. J. SPSS15.0 Statistical procedures companion. Upper Saddle River, NJ: Prentice Hall;2015.

7. Powell, E. T. Program development and evaluation, analyzing quantitative data. Board of Regents of the University of Wisconsin System Cooperative Extension Publications, Madisson, Wisconsin. Retrieved from http://learningstore,uwex.edu/pdf/G3658-6. pdf on July 25, 2016, 1:00AM.

8. Cruz, E. S. Rating Philippine universities. The Philippine Star. Retrieved from http:// www.philstar.com/opinion/2016/01/03/ 1538697/rating-philippine-universities on August 3, 2016 at 4:15 PM.

9. Handbook on typology, outcomes-based education, and institutional sustainability Assessment. 2014, p.24

10. Guidelines, policies and standards commission on higher education (CHED). 2016. 